\title{
227 Early detection of systolic and diastolic dysfunction in asymptomatic hypertrophic cardiomyopathy mutation carriers using cardiac magnetic resonance imaging
} Tjeerd Germans*1, Marco JW Gotte ${ }^{1}$, Iris K Russel ${ }^{1}$, Marieke D Spreeuwenberg1, J Tim Marcus ${ }^{1}$, Yigal M Pinto², Pieter A Doevendans ${ }^{3}$, Arthur AM Wilde ${ }^{4}$ and Albert C van Rossum ${ }^{1}$

Address: ${ }^{1}$ VU University Medical Center, Amsterdam, The Netherlands, ${ }^{2}$ Academic Hospital Maastricht, Maastricht, The Netherlands, ${ }^{3}$ University Medical Center Utrecht, Utrecht, The Netherlands and ${ }^{4}$ Academic Medical Center, Amsterdam, The Netherlands

* Corresponding author

from I ${ }^{\text {th }}$ Annual SCMR Scientific Sessions

Los Angeles, CA, USA. I-3 February 2008

Published: 22 October 2008

Journal of Cardiovascular Magnetic Resonance 2008, I0(Suppl I):A88 doi:I0.I I86/I532-429X-10-SI-A88

This abstract is available from: http://jcmr-online.com/content/I0/SI/A88

(c) 2008 Germans et al; licensee BioMed Central Ltd.

\section{Background}

Hypertrophic Cardiomyopathy (HCM) is characterized by asymmetric hypertrophy of the left ventricle (LV). While over $400 \mathrm{HCM}$ mutations have been identified, increasing number of HCM mutation carriers without hypertrophy have been detected. No data on regional functional and structural abnormalities in HCM mutation carriers before the development of hypertrophy are yet available. With cardiac magnetic resonance imaging (CMR), both regional function and structure can accurately be evaluated.

\section{Methods}

28 HCM mutation carriers from 9 different families and 28 age- and gender matched controls, of whom 15 were genotype negative family members of HCM mutation carriers, underwent CMR. The imaging protocol included full coverage of the LV and left atrium with cine imaging. Subsequently, three short axis slices at basal, mid and apical level were obtained with myocardial tissue tagging (temporal resolution $14 \mathrm{~ms}$, tag persistence $>1000 \mathrm{~ms}$ ). Finally, delayed contrast enhancement imaging was performed. From these datasets, global LV dimensions and left atrial volumes, end-diastolic wall thickness, septal-tolateral-wall-thickness ratio (SL-ratio), wall thickening, peak systolic circumferential strain (peak SCS), peak systolic circumferential strain rate (peak SCSR), peak diastolic circumferential strain rate (peak DCSR) were determined.

\section{Results}

Global LV dimensions were comparable between both groups. No contrast enhancement was found. Crypts were present in the inferoseptum in 23 of $28 \mathrm{HCM}$ mutation carriers $(82 \%)$ and in none of the controls. SL-ratio was larger in HCM mutation carriers than in controls $(1.3 \pm$ 0.21 versus $1.1 \pm 0.13, \mathrm{p}<0.001$ ), see Figure 1 . In HCM mutation carriers, wall thickening in inferoseptal segments at basal and mid level was lower compared to controls $(0.61 \pm 0.31$ versus $0.77 \pm 0.26, \mathrm{p}<0.01)$.

Peak SCS was comparable in the septum $(-16.8 \pm 3.0$ versus $-16.4 \pm 2.7, \mathrm{p}=\mathrm{ns}$ ) which may result from pseudonormalization due to the regional crypt formation. Peak SCS was lower in the lateral segments in HCM mutation carriers compared to controls $(-17.7 \pm 3.4 \%$ and $-19.9 \pm 3.4 \%$, $\mathrm{p}<0.05)$. Peak SCSR was lower in the basal inferoseptal and lateral segments in HCM mutation carriers compared to controls $\left(-107 \pm 14.0 \% . \mathrm{s}^{-1}\right.$ versus $-119 \pm 18.7 \% . \mathrm{s}^{-1}, \mathrm{p}<$ 0.05). Peak DCSR was lower in all segments in HCM mutation carriers compared to controls (mean $99.2 \pm$ $28.79 \% . \mathrm{s}^{-1}$ versus $\left.114 \pm 33.2 \% . \mathrm{s}^{-1}, \mathrm{p}<0.001\right)$. With 


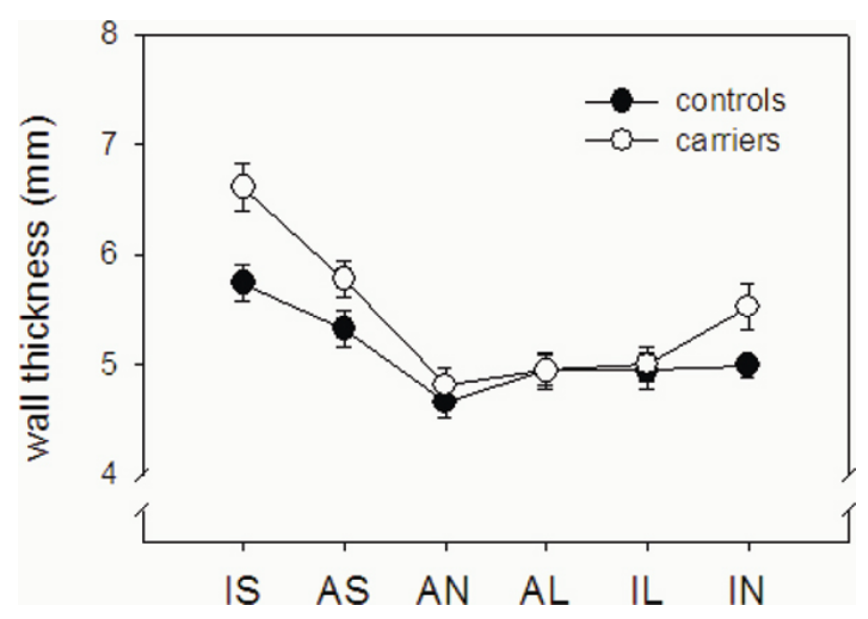

Figure I

Systolic and diastolic dysfunction and subsequent left atrial dilation are present in hypertrophic cardiomyopathy mutation carriers before the development of overt hypertrophy. Asymmetric wall thickening is associated with crypt formation with occurs in 82 percent of hypertrophic cardiomyopathy mutation carriers.

increase of end-diastolic wall thickness, peak SCS and peak SCSR were maintained, while peak DCSR decreased see Figure 2. In line with the observed decrease in peak DCSR, a marker of diastolic dysfunction, left atrial maximum volume was larger in HCM mutation carriers compared to controls $\left(56 \pm 11.7\right.$ versus $51 \pm 6.4 \mathrm{ml} . \mathrm{m}^{-2}$, p < 0.05).

\section{Conclusion}

Functional abnormalities, characterized by reduced systolic and diastolic strain and strain rate are present in HCM

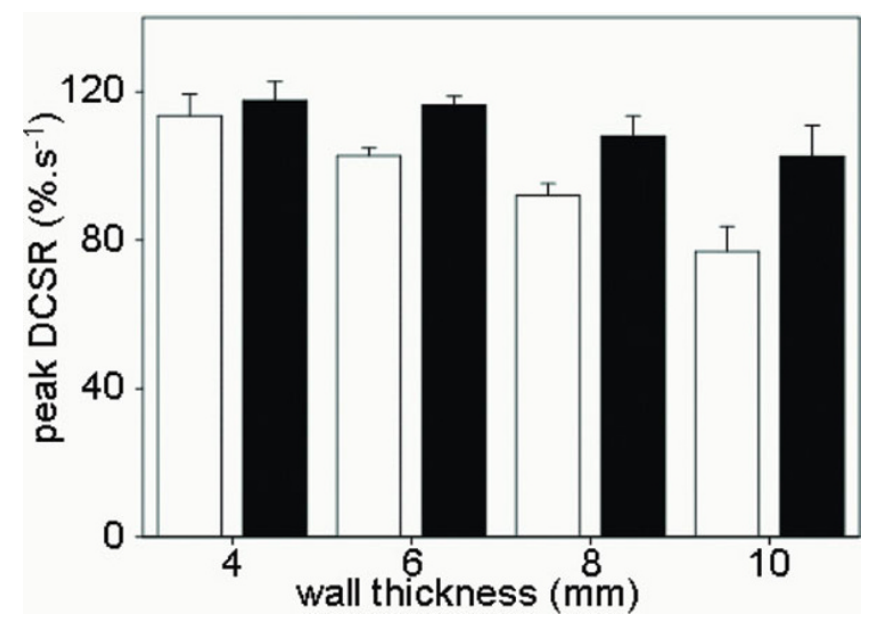

Figure 2 mutation carriers without manifest hypertrophy. In addition, these patients exhibit structural abnormalities including septal to lateral asymmetry in left ventricular wall thickness and the presence of crypts. These structural abnormalities and decreased regional peak DCSR may thus be recognized as important, early identification of asymptomatic HCM mutation carriers.
Publish with BioMed Central and every scientist can read your work free of charge

"BioMed Central will be the most significant development for disseminating the results of biomedical research in our lifetime. " Sir Paul Nurse, Cancer Research UK

Your research papers will be:

- available free of charge to the entire biomedical community

- peer reviewed and published immediately upon acceptance

- cited in PubMed and archived on PubMed Central

- yours - you keep the copyright

Submit your manuscript here:

http://www.biomedcentral.com/info/publishing_adv.asp 